\title{
Undergraduate Health Professional Student Perceptions/Attitudes towards Interprofessional Education (IPE): A Qualitative Study
}

\author{
A. D. P Perera \\ Department of Physiotherapy, Faculty of Allied Health Sciences, General Sir John Kotelawala Defence University, Sri Lanka
}

\begin{abstract}
The introduction of IPE into healthcare professions' curricula has become an important aim globally. The aim of this paper is to investigate the comments of different health professional students regarding IPE. This will illuminate the issues impacting on health professional teams and the needs and challenges for IPE in Sri Lanka. A cross sectional study was conducted with 541 students who have had prior clinical training for a period of one year, from 3 health professional groups (Medical, Physiotherapy, Nursing diploma, Nursing degree) at different health educational institutions. The free comments regarding IPE were considered. The comments were analyzed independently. Five key themes emerged from the analysis of the transcription: (1) Patients benefits from IPE (29.4\%) (2) Enable to facilitate team work skills in to clinical practice (24.5\%). Enhance communication skills and IPE (16.8\%); (4) Barriers to practicing IPE (12.6\%); (5) Development of health education institutions (9.8\%). IPE is an essential component in helping to develop good working relationship, attitudes and behavior. Using IPE to practice is much desired but often faces practical barriers. It is proposed that IPE is most effective in promoting patient care, teamwork and communication skills.
\end{abstract}

Keywords: Interprofessional education, attitudes,

\section{Introduction}

IPE is recognized as an important component for life-long learning among healthcare professionals to strengthen Interprofessional practice [1,2]. The different professional's works together to enhance health care service is not a new concept [3]. The collaboration learning occurred with joint education programs [4-6]. Interprofessional education, which is designed to promote good working relationships between different health professionals by promoting positive interprofessional attitudes and behaviors [7-9]. It is proposed that IPE is most effective in promoting teamwork of different professionals who have a clear sense of their own professional identity and have experiences to share [10-12]. The interprofessional collaboration improves the quality of patient care [13-17]. Previous research studies had shown that several benefits of IPE; group and organizational relationships [15]; creativity in teaching and research activities [16]; Interprofessional communication [17-19]; and cost effectiveness for the higher education institutions [12]. Teams with greater cohesiveness are associated with better clinical outcomes and higher patient satisfaction [20]. Evidences in interprofessionals practice revealed that the most successful intervention in chronic disease management is ensured by working together with different health professionals $[\mathbf{2 1 , 2 2 ]}$. But, literature also identified that few barriers to practice IPE [23].

The introduction of IPE into higher education institutions has become an important object for governments and universities internationally. In Sri Lanka, few higher education institutions were established to provide health professionals degrees, but it is rather limited to gain evidences that these institutions will provide for the collaborative learning. Therefore, the health care professionals interact poorly with each other during their basic health professions education.
The aim of this paper is to investigate the free comments regarding the perceptions (including attitudes) towards Inter Professional Education amongst pre-registration students in the different health professions in Sri Lanka. This information will be useful to understand the issues influencing health professional teams and the needs and challenges for interprofessional education.

\section{Materials and Methods}

A cross sectional study was conducted with the students who have had prior clinical training for a period of one year, from 3 health professional groups (Medical, Physiotherapy, Nursing Diploma, Nursing degree) at different health educational institutions. Second year students were selected to the study as they listen to patient stories and communicate with one another about their roles within the health care system. A total of five hundred forty one 541 students were invited to present their free comments on IPE. The free comments were made with their informal exposure to the IPE. The comments were analyzed independently by the principal author according to the principles of thematic analysis. Medical and physiotherapy students were selected at Faculty of Medicine, University of Colombo. Nursing diploma students were selected at National Training School, Colombo. Nursing degree students were selected from Faculty of Medical Sciences, University of Sri Jayewardenepura. Ethical clearance was obtained from the Ethics Review Committee, Faculty of Medicine, University of Colombo (EC/ 13/ 016).

\section{Results}

The response rate for the survey was 143/541 (20.84\%). Gender distribution was Female: $73.0 \%$; Male: $24.9 \%$. The analysis of the free comments identified several emerging 


\section{International Journal of Science and Research (IJSR) \\ ISSN (Online): 2319-7064}

Index Copernicus Value (2013): 6.14 | Impact Factor (2015): 6.391

themes (Table 1). Of the identified themes, five were consistently present across the study sample. These five themes were considered as the 'major' themes, with results presented below.

Table 1: Identified major themes of free comments of IPE.

\begin{tabular}{|l|c|}
\hline Major theme & Rate (\%) \\
\hline I. Patients benefits from IPE & 29.4 \\
\hline $\begin{array}{l}\text { II. Enable to facilitate team work skills in to clinical } \\
\text { practice. }\end{array}$ & 24.5 \\
\hline III. Enhance communication skills and IPE. & 16.8 \\
\hline IV. Barriers to practicing IPE & 12.6 \\
\hline $\begin{array}{l}\text { V. Development of the higher education institution } \\
\text { through IPE }\end{array}$ & 9.8 \\
\hline
\end{tabular}

\section{Summary of Themes}

\section{(I) Patients benefits from IPE}

The majority of health professional students mentioned that the ultimate benefit of IPE goes for the better outcome in patients $(29.4 \%)$. It will provide the best support for the patient. Better teamwork between different health professionals improves patient outcomes.

"IPE has to be improved as it is vital for better outcome in patient's conditions. Therefore; practically this should be conducted anyhow".(Physiotherapy student)

In general, IPE aims to improve patient safety, enhance patient satisfaction, and increase levels of innovation in patient care. IPE will establish education strategies that enhance collaborative working among different professionals along with profession-specific skills on providing safe and effective health care for the patients and community.

"Patient's can get more effective services from different health professionals through IPE”.'(Nursing student)

"Patients will exposure to the best treatment approaches and this will provide the protection of patient's conditions". (Medical Student)

\section{(II) Enable to facilitate team work skills in to clinical practice}

The majority of students stated that team skills are important for maintaining safety in both patients and health professionals as multidisciplinary teams. The interprofessional practice is often limited by poor leadership of teams, the effects of professional socialization and impact of organizational change. It has been noted that gains in patient care can be improved when staff regularly interact to negotiate and discuss upon their work.

"IPE will allow us to use our own experience in to clinical practice and to get ideas about our own responsibilities". (Physiotherapy student).

"I think, IPE will give us to learn team skills and it is important for our future profession and it is more benefit for the field of health care professions". (Medical student)
"As a nursing student, I believe that the team work is important to fulfill the patient care. To become a member in this team; we can build good understanding among different health professionals and respect for them".

Best management of the patient can be achieved through team work concept.

"This will be a good opportunity to increase working capacity and accuracy of profession. This will lead to the best management of the patient condition".

\section{(III) Enhance communication skills and IPE.}

Communication skills are important skills expected in working in a health care team. Communication and team work are interrelated. Poor communication between team members and with patients or carers, can impact negatively on patient safety.

"I think, good communication is very important to share ideas and experiences among different health professional. This will allow us to listen to individual viewpoints". (Physiotherapy student)

"I think, this will be the best opportunity to make good understanding with each member". (Nursing student)

"IPE is very much useful us as medical professionals. Actually it is more helpful for the clinical decision making for patients. (Medical Student)

\section{(IV) Barriers to practicing IPE.}

Some students stated that it is difficult to carry out IPE goals in Sri Lankan educational set ups as they have lack of opportunities to interact each others. Now it is high time to establish interprofessional education to enhance the best health care services for the patient.

"I think, all the professional group's gain the leadership position, other than one profession is leading and others follow".(Physiotherapy student)

"It is difficult to practice IPE due to lack of awareness of healthcare professionals about their roles and importance of their involvement to the betterment of the patent".)(Nursing student)

"IPE is good, but I think, this will create unnecessary problem during study time. There should be some platform where medical students interact with other health care students to work as a team". (Medical student)

\section{(V) Development of the higher education institutions through IPE.}

Less number of students stated that Interprofessional education (IPE) can bring benefits to the higher education institutions will promote effective interprofessional collaboration (IPC) across healthcare, professional education, and government sectors. Integration of professional 


\section{International Journal of Science and Research (IJSR) \\ ISSN (Online): 2319-7064}

Index Copernicus Value (2013): 6.14 | Impact Factor (2015): 6.391

education is a major trend in higher education and it will cost effectiveness for the institutions.

"I think, we have to think that how IPE is important to development of our higher education institutions. It is a great opportunity to utilize the resources maximally in the institutions".'(Nursing and Medical student)

The collaborative research activities of different health professionals are important for the development of health care sector

"Health care professionals can do some researches together regarding patient's problems and then it will make a knowledge and skill full professionals".(Physiotherapy student)

\section{Discussion}

The present study had shown that the majority of students stated that the IPE is more beneficial for the best support of the patient care. Findings from previous literature also showed that the IPE can enhance collaborative knowledge and skills to improvements in the delivery of the best patient care [24-26]. Students in the present study stated that IPE will allow them to use their own experience in the multidisplinary team and enhance the team work skills. IPE will challenge for stereotypes and it allows students to strengthen their own professional identities [16,27]. Students of the present study gained a greater understanding of other professions' roles and skills and began developing skills in interprofessionals teamwork. This is in lined with a past study revealed that students can build good understanding among different health professionals and respect for each other [12]. IPE is important for the development of interpersonal skills and IPE engenders a respect for and understanding of the role of other professions [16,27].

In the present study, students noted that good communication is very important to share ideas and experiences between different health professionals. This will allow them to listen to individual viewpoints [17]. IPE will enhance personal and professional confidence, promote mutual understanding between professions, facilitate intra and interprofessional communication and encourage reflective practice [17]. IPE will lead to the development of necessary communication skills to operate effectively in the multidisplinary team [12].

Literature identified that few barriers to practice IPE which is often limited by weak relationship among different health professionals, poor leadership of teams, the effects of professional socialization, status differentials between

practitioners, and the impact of institutional change [23]. Students in the present study also identified that poor leadership position as a barrier for practicing IPE. IPE is important for students to recognize the overlapping professional function [12]. Some students in the present study also stated that it is important to identify the platform where different health professional students interact with each other to work as a team. Meaningful IPE experience can better prepare students for encounting the complexities of real life Interprofessional problems.

Few students in the present study stated that the IPE is important to the development of the higher education institutions. IPE can bring benefits to the higher education institutions [12]. Students showed that IPE enhances the collaborative research regarding patient's problems and then it will make knowledge and skill full professionals in future practice. This finding is in lined with a previous study [16] found that IPE can promote creativity in teaching and research.

\section{Conclusion}

Most students perceived that IPE is an essential component in helping to develop good working relationship, attitudes and behavior among different health professions. It is observed that IPE is most effective in promoting patient care, teamwork and communication skills. Even though IPE practice is much desired there are practical barriers as well. Many comments were based on the Inter professional practice (IPP); therefore, it is important to introduce IPE into Sri Lanka. This study indicates important considerations in customizing IPE experiences to the Sri Lankan Health Context and that certain focused approaches need to be developed for IPE in Sri Lanka.

\section{Acknowledgement}

The author would like to acknowledge student participants and other staff for their support and collaboration during the study.

\section{References}

[1] D'Amour, D., \& Oandasan, I. Interprofessionality as the field of interprofessional practice and interprofessional eduation: An emerging concept. Journal of Interprofessional Care, 2005; 19(S1), 8-20.

[2] Oandasan, I., \& Reeves, S. Key elements for interprofessional education. Part 1, The learner, the educator and the learning context. Journal of Interprofessional Care, 2005; 19(S1), 21-38.

[3] Basset T, Bryson T (1989) A bridge to learning. Health Service Journal 1989; 99: 1246-7.

[4] HMSO (1988) (The Griffiths Report) Community Care Agenda for Action. HMSO, London.

[5] Pearson $P$, Spencer J. Pointers to efi ${ }^{\wedge}$ ective teamworking: exploring primary care,J Interprof Care 1995; 9: 131-8.

[6] Molyneux J (2001) Interprofessional teamworking: what makes teams work weU?J Interprofessional Care 2001; 15(1): 29-35.

[7] Leathand A (ed). (Zoing Inter-professional. Working Together for Health \& Welfare. 1994; Roudedge, London. 


\section{International Journal of Science and Research (IJSR) \\ ISSN (Online): 2319-7064}

Index Copernicus Value (2013): 6.14 | Impact Factor (2015): 6.391

[8] Caldwell K. Atwal A. The problems of interprofessional healthcare practice in hospitals. BrJ Nurs 2003; 12(20): 1212-18.

[9] Barr, H., Waterton, S. Interprofessional Education in Health and Social Care, The Report of a United Kingdom Survey, 1996; CAIPE, London.

[10] Funnell, P. Exploring the Value of Interprofessional Shared Learning: Interprofessional Relations in Health Care. 1995; Edward Arnold, London.

[11] Pirie, P.L. Evaluating community health promotionprograms. In: Bracht, N. (Ed.), Health Promotion at the Community Level: 2. 1999; New Advances. Sage Publications, London.

[12] Iiiingworth, P., Cheivanayagam, S. Benefits of Interprofessional Education in Health Care, British Journal of Nursing, 2007, 16(2): 121-124.

[13] Schmitt, M.H. Collaboration improves the quality of care: Methodological challenges and evidence from US healthcare research. Journal of Interprofessional Care, 2001; 15(1), 47-66.

[14] Zwarenstein, M., \& Reeves, S. Knowledge translation and interprofessional collaboration: Where the rubber of evidence based care hits the road of teamwork. Journal of Continuing Education for the Health Professions, 2006; 26(1), 46-54.

[15] Barr H. Freeth D, Hammick M, Koppel I. Reeves S. Evaluations of Interprofessional Education:A United Kingdom Revieti'for Health and Social Care. Review, (2000a); UK Center for the Advancement of Interprofessional Education/ British Educational Research Association. London.

[16] McCroskey J.i^obertson PJ. Challenges and Benefits of Interprofessional Education: Evaluation ofthe InterProfessional Initiative at the University of Southern California, Teacher Education Quarterly (Fall): 1999; 69-8.

[17] Barr H. Interprofessional Education: (2000b). A Review. United Kingdom Central Council of Nursing, Midwifery and Health Visiting, London.

[18] Mariano C. The case for interdisciplinary collaboration.NursOutlook ; 1999; 37 (6):285-8.

[19] Koppel I. Evaluation of Interjnofessional Education: State of Art: Tlie IPE JET Study. 1998; BEWA, Queen's University. Belfast.

[20] Grumbach K ,Bodenheimer T; Can Health Care Teams Improve Primary Care Practice JAMA. 2004; ;291(10).

[21] Calkins E, Boult C, Wagner EH, Pacala J; New ways to care for older people. 1998; New York: Springer.

[22] Wagner EH, Davis C, Grothaus L, Wallace J, LeGerfo $\mathrm{M}$, et al. Preventing disability and managing chronic illness in frail older adults: a randomized trial of a community-based partnership with primary care. J Am GeriatrSoc 1998; 46:1191-1198.

[23] Simpson, A., Bowers, L., Alexander, J., Ridley, C., \& Warren, J. Occupational therapy and multidisciplinary working on acute psychiatric wards: The Tompkins acute ward study. British Journal of Occupational Therapy, 2005; 68(12), 545-552.

[24] Barr, H., Koppel, I., Reeves, S., Hammick, M., \& Freeth, D.S. Effective interprofessional education: Assumption, argument and evidence. 2005; London: Blackwell Science.
[25] Reeves, S., Zwarenstein, M., Goldman, J., Barr, H., Freeth, D.S., Hammick, M., \& Koppel, I. Interprofessional education: Effects on professional practice and healthcare outcomes. 2008; Cochrane Database of Systematic Reviews, Art.

[26] Barrett, J., Curran, V., Glynn, L., \& Godwin, M. CHSRF synthesis: Interprofessional collaboration and quality primary healthcare. 2007. Canadian Health Services Research Foundation.

[27] Connor C, I^ees S (1997) Ways forward for shared learning between nursing and social work students. Nurse Educ Today 1997; 17: 494-501.

\section{Author Profile}

A.D.P Perera received the BSc Physiotherapy (Hons) and MSc Exercise \& Sport Science degrees from University Colombo (2011) and University of Peradeniya (2015) Sri Lanka, respectively. She is a lecturer at Department of Physiotherapy, Faculty of Allied Health Sciences, General Sir John Kotelawala Defence University, Sri Lanka. 